\title{
Residual symptoms and functioning in depression, does the type of residual symptom matter? A post-hoc analysis
}

Irene Romera ${ }^{1,2^{*}}$, Víctor Pérez ${ }^{3}$, Antonio Ciudad ${ }^{1}$, Luis Caballero ${ }^{4}$, Miguel Roca ${ }^{5}$, Pepa Polavieja ${ }^{1}$ and Inmaculada Gilaberte ${ }^{1}$

\begin{abstract}
Background: The degrees to which residual symptoms in major depressive disorder (MDD) adversely affect patient functioning is not known. This post-hoc analysis explored the association between different residual symptoms and patient functioning.

Methods: Patients with MDD who responded ( $\geq 50 \%$ on the 17-item Hamilton Rating Scale for Depression; HAMD-17) after 3 months of treatment (624/930) were included. Residual core mood-symptoms (HAMD-17 core symptom subscale $\geq 1$ ), residual insomnia-symptoms (HAMD-17 sleep subscale $\geq 1$ ), residual anxiety-symptoms (HAMD-17-anxiety subscale $\geq 1$ ), residual somatic-symptoms (HAMD-17 Item $13 \geq 1$ ), pain (Visual Analogue Scale 230), and functioning were assessed after 3 months treatment. A stepwise logistic regression model with normal functioning (Social and Occupational Functioning Assessment Scale $\geq 80$ ) as the dependent variable was used.

Results: After 3 months, 59.5\% of patients (371/624) achieved normal functioning and 66.0\% (412/624) were in remission. Residual symptom prevalence was: core mood symptoms 72\%; insomnia 63\%; anxiety 78\%; and somatic symptoms $41 \%$. Pain reported in $18 \%$. Factors associated with normal functioning were absence of core mood symptoms (odds ratio [OR] 8.7; 95\% confidence interval [Cl], 4.6-16.7), absence of insomnia symptoms (OR 1.8; 95\% $\mathrm{Cl}, 1.2-2.7$ ), episode length (4-24 weeks vs. $\geq 24$ weeks [OR 2.0; 95\% Cl, 1.1-3.6]) and better baseline functioning (OR 1.0; $95 \% \mathrm{Cl}, 1.0-1.1)$. A significant interaction between residual anxiety symptoms and pain was found ( $p=0.0080)$.

Conclusions: Different residual symptoms are associated to different degrees with patient functioning. To achieve normal functioning, specific residual symptoms domains might be targeted for treatment.
\end{abstract}

Keywords: Residual symptoms, Major depression, Functioning

\section{Background}

Residual symptoms of depression cause significant functional impairment [1,2]. This has been reported in patients who respond but are not remitters, partial remitters [1,2], and even in remitters (typically defined as a score of $\leq 7$ on the 17-item Hamilton Depression Rating scale [HAMD-17]) with residual symptoms [2]. Residual symptoms are also associated with persistent functional impairment [1]. However, little is known

\footnotetext{
* Correspondence: romera_irene@lilly.com

'Department of Clinical Research Lilly, S.A. Avenida de la Industria 30, 28108, Alcobendas, Spain

${ }^{2}$ Autonomous University of Barcelona, Barcelona, Spain

Full list of author information is available at the end of the article
}

about the role of specific residual symptom domains, such as core symptoms, symptoms of anxiety, somatic symptoms, and non-painful symptoms.

Most research in patients with residual symptoms has focused on the relationship between residual symptoms and depressive relapse. Several studies have shown an increased risk of relapse [3,4] and rapid relapse [5] in patients with residual symptoms after response without remission. A posthoc analysis from the Sequenced Treatment Alternatives to Relieve Depression [6] study showed that a greater number of residual symptom domains were associated with a higher probability of relapse in full symptomatic remitters. Although a few studies have evaluated the impact of residual symptoms

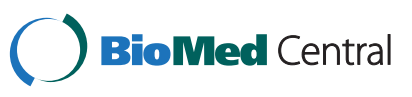


on functional impairment $[1,2,7,8]$, to our knowledge, no published studies have examined the specific role of each residual symptom domain on functional impairment. This is definitely an area worthy of investigation, since the aim of treating depression is not only to achieve clinical remission, but also to return the patient to previous levels of functioning [9]. Knowledge of which residual symptom domains are associated with significant functional impairment and, to what degree would assist physicians in the implementation of specific strategies and treatments to increase the chances of achieving normal or previous levels of functioning.

The aim of this posthoc investigation was to assess the association of specific residual symptoms (core mood, insomnia, anxiety, somatic, and pain) with patient functioning in a large group of patients with an episode of major depressive disorder (MDD) who responded after 3 months of acute antidepressant treatment in routine clinical practice. Our hypothesis was that the strength of the association between residual symptoms and functioning would differ depending on the type of residual symptom.

\section{Methods}

This study is a post-hoc analysis done on a group of MDD patients who responded (improvement of $\geq 50 \%$ on the HAMD-17) after 3 months of acute treatment $(n=624)$. The analysis of the association between residual symptoms and functioning was done at three months of acute treatment. The source of data was based on a 1-year prospective observational study of a cohort of 930 outpatients with an index MDD episode [10]. As a non-interventional study, the patients were treated according to everyday clinical routine. The protocol was approved by the ethical review board of the Hospital Puerta de Hierro in Madrid, Spain, and all patients provided written informed consent before their inclusion in the study.

\section{Participants}

As described in detail elsewhere [10], adult outpatients with nonpsychotic MDD, single or recurrent episode, according to DSM-IV-TR ${ }^{\circledR}[11]$ were included. Patients had a baseline total score of $\geq 15$ on the HAMD-17) [12] and at least a moderate $(\geq 4)$ baseline score on the Clinical Global Impression-Severity (CGI-S) scale [13]. Patients suffering from Axis I main psychiatric disorder, dementia, Alzheimer's disease, organic brain syndrome, or cognitive impairment were excluded from the study.

Patients from this study who responded (improvement of $\geq 50 \%$ on the HAMD-17) after 3 months of acute antidepressant treatment were included in the present analysis.

\section{Measures and definitions}

The HAMD-17 was used to assess the severity of depression and its improvement. Remission was defined as a HAMD-17 score of $\leq 7$ and a response as an improvement of $50 \%$ or more from the baseline score. Functioning was measured using the Social and Occupational Functioning Assessment Scale (SOFAS) [14], a 100-point single-item scale used to indicate the individual's level of social and occupational functioning across a continuum ranging from a state of optimum functioning to a state of important functional impairment. It measures only the level of social and occupational functioning without taking symptoms into account. Thus, a value of 1 represents the hypothetically most impaired individual and 100 the hypothetically healthiest individual. It is completed by a clinician using information from any clinical source. The two highest ranges on the SOFAS, 81-90 and 91-100, describe individuals who not only are without significant psychopathology, but who also exhibit many traits often considered to be components of positive mental health. A SOFAS score $\geq 80$ was used to define normal levels of functioning [15]. The baseline and 3 -month follow-up visits were included in this analysis.

Based on Dombrovski [16], we defined the presence of residual core mood symptoms as a score of 1 or more on the HAMD-17 core symptom subscale (depressed mood [Item 1], guilt [Item 2], suicide [Item 3], and anergia/anhedonia [Item 7]). The presence of residual insomnia symptoms was defined as a score of 1 or more on the HAMD-17 sleep subscale insomnia items (early [Item 4], middle [Item 5], and late [Item 6]). The presence of residual anxiety symptoms was defined as a score of 1 or more on the HAMD-17 anxiety subscale (agitation [Item 9], psychic anxiety [Item 10], somatic anxiety [Item 11], and hypochondriasis [Item 15]), and of residual somatic symptoms as a score of 1 or more for item 13 of the HAMD-17.

The Visual Analog Scale (VAS) for Pain was used to assess pain [17], defining the presence of pain as a VAS-overall pain $\geq 30 \mathrm{~mm}$, which includes patients with at least moderate pain, and had been previously used for the identification of clinically significant pain [18]. The visual analog scale for pain is an instrument widely used in research studies to measure the level of pain. Its simplicity, reliability, and validity, make the VAS the optimal tool for describing pain $[19,20]$. Pain was measured by the VAS- overall pain, where the patient scores on a 100 point scale the level of overall pain in the last week.

\section{Analysis}

Demographic and clinical data at baseline were described by means of percentages (qualitative variables) or mean \pm standard deviation (quantitative variables). 
A stepwise logistic regression model was developed to evaluate the association between the residual symptom domains and patient functioning, with a normal level of functioning after 3 months of antidepressant treatment (SOFAS total score $\geq 80$ ) as the dependent variable, and the following factors as the independent variables in the initial model: Age as a continuous variable, gender, marital status, working status, education status, baseline functioning (SOFAS score), baseline depression severity (HAMD-17), presence of previous episodes of depression, medical co-morbidities, length of current episode, residual symptoms at 3 months (core mood symptoms, insomnia symptoms, anxiety symptoms, somatic symptoms), and pain at 3 months. All the independent variables were included in a full model and then removed stepwise by backward selection (threshold for the p-value $=0.05$ ). Interactions between variables were tested at 3 months (likelihood ratio). Only patients with complete information on the variables previously described were included in the model $(n=600)$. The reduced model was reported in terms of odds ratios (OR) and their 95\% confidence intervals (CI); the fit of the final model was assessed using the Hosmer-Lemeshow goodness-of-fit test [21].

Receiver operating characteristics curves were plotted to determine and compare the sensitivity and specificity of the residual symptom domains and of the pain, as indicators of normal levels of functioning according to the SOFAS (SOFAS score $\geq 80$ ) after 3 months of treatment. Areas under the curve (AUC) using the trapezoidal rule and their associated asymptotic 95\% CIs were calculated. The AUC varies from 0.5 (no apparent accuracy) to 1.0 (perfect accuracy). SAS 9.2 for Windows (SAS Institute Inc., USA) was used for the statistical analysis.

\section{Results}

\section{Patient disposition, demographics, and clinical} characteristics

Of the evaluable sample $(\mathrm{N}=930), 624$ patients responded to antidepressant treatment and were therefore included in the present analysis. Table 1 shows the socio-demographic and clinical characteristics of the study sample of responders.

\section{Residual symptom prevalence}

After 3 months of acute antidepressant treatment, the most frequent residual symptom was anxiety in $78.2 \%$ of patients (95\% CI, 74.8-81.4), followed by core mood symptoms in $72.1 \%$ (95\% CI, 68.4-75.6), residual insomnia in $63.0 \%$ (95\% CI, 59.1-66.8) and somatic symptoms in $41.3 \%$ (95\% CI, 37.4-45.3). Pain was reported in $18.4 \%$ (95\% CI, 15.5-21.7) of patients (Figure 1A). The severity of the residual symptoms and pain was mild (Table 2).
Table 1 Baseline demographic and clinical characteristics

\begin{tabular}{lc}
\hline Characteristics & $\mathbf{N}=\mathbf{6 2 4}$ \\
\hline Age, years, mean (SD) & $47.6(13.8)$ \\
\hline Gender, $\mathrm{n}(\%)$ & \\
\hline Women & $408(65.4)$ \\
\hline Ethnicity, $\mathrm{n}(\%)$ & $611(97.9)$ \\
\hline Caucasian & \\
\hline Marital status, n (\%) & $379(60.7)$ \\
\hline Married & $132(21.1)$ \\
\hline Single & $113(18.1)$ \\
\hline Other &
\end{tabular}

Education, $\mathrm{n}(\%)$

\begin{tabular}{ll}
\hline Illiterate & $12(1.9)$ \\
\hline Basic school education & $252(40.4)$ \\
\hline High school/higher education & $316(50.6)$ \\
\hline Employment status, $\mathrm{n}(\%)$ &
\end{tabular}

Active 264 (42.3)

Not working (unemployed or sick leave) $148(23.7)$

\begin{tabular}{ll}
\hline Other $^{2}$ & $212(34.0)$
\end{tabular}

Patients with medical comorbidity, $\mathrm{n}(\%) \quad 339$ (54.3)

Family psychiatric history, $\mathrm{n}(\%) \quad 221$ (35.4)

Number of previous episodes, mean (SD) 2.6 (2.5)

\begin{tabular}{ll}
\hline Patients with 1st episode, $\mathrm{n}(\%)$ & $280(44.9)$ \\
\hline
\end{tabular}

Age at first episode of depression, mean (SD) 40.5 (14.0)

Current depressive episode:

Length, mean weeks (SD) $13.9(23.5)$

Chronicity $\geq 2$ years, $\mathrm{n}(\%) \quad 38$ (6.1)

HAMD-17 total score, mean (SD) 24.6 (5.7)

Residual symptoms, mean (SD)

\begin{tabular}{ll}
\hline Core mood $^{3}$ & $8.7(2.3)$ \\
\hline Insomnia $^{4}$ & $3.9(1.4)$ \\
\hline Anxiety $^{5}$ & $6.2(2.2)$ \\
\hline Somatic $^{6}$ & $1.1(0.6)$ \\
\hline VAS-overall pain, total score (mean) & $41.4(28.2)$ \\
\hline Monotherapy, $\mathrm{n}(\%)$ & $550(88.1)$ \\
\hline SSRI & $145(26.4)$ \\
\hline SNRI & $387(70.3)$ \\
\hline Tricyclic antidepressants & $6(1.1)$ \\
\hline Others & $12(2.2)$ \\
\hline Combination of antidepressants, $n$ (\%) & $74(11.9)$ \\
\hline
\end{tabular}

MDD = Major depressive disorder; SSRI = Selective serotonin reuptake inhibitor; SNRI = Serotonin-norepinephrine reuptake inhibitor; SD = Standard deviation; VAS = Visual Analog Scale; ${ }^{1}$ Widowed, separated, divorced and other;

${ }^{2}$ Student, housekeeping, retired, disabled worker; ${ }^{3}$ depressed mood [Item 1], guilt [Item 2], suicide [Item 3], and anergia/anhedonia [Item 7] of the HAMD-17; ${ }^{4}$ early [Item 4], middle [Item 5], and late insomnia [Item 6] of the HAMD-17; ${ }^{5}$ agitation [Item 9], psychic anxiety [Item 10], somatic anxiety [Item 11], and hypochondriasis [Item 15] of the HAMD-17; ${ }^{6}$ item 13 of the HAMD-17. 


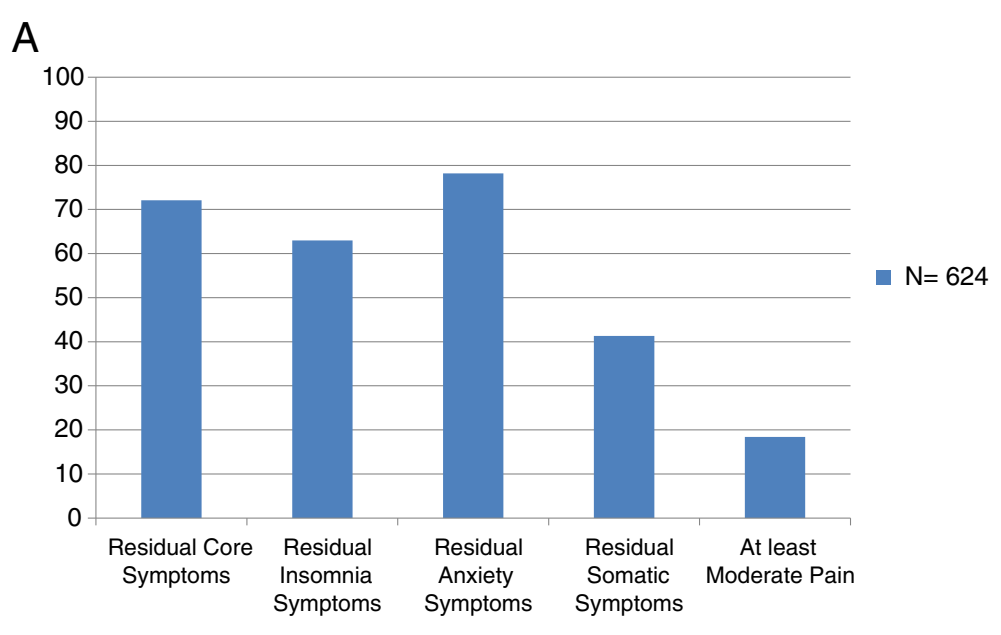

B

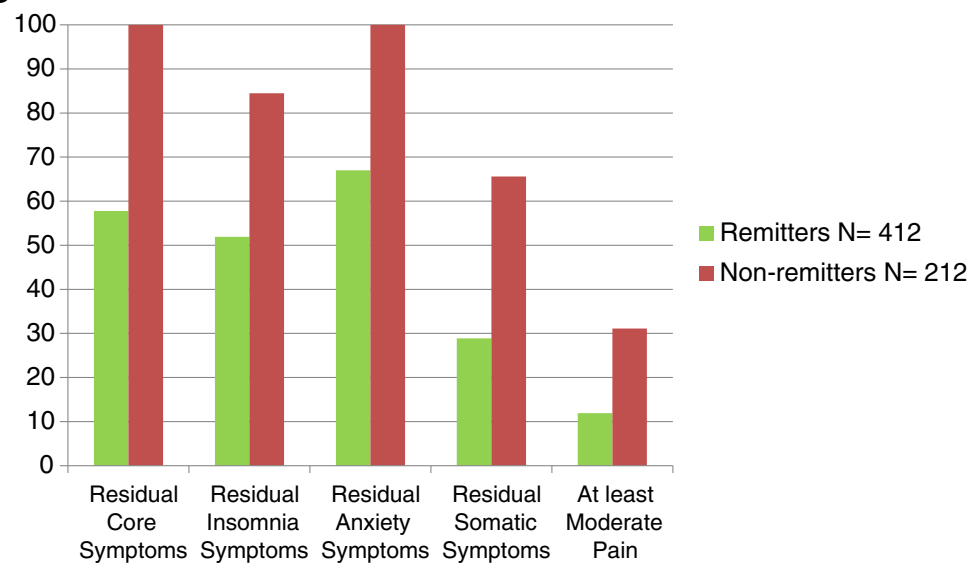

Figure 1 A Prevalence of residual symptoms domains and pain. All patients, $N=624$. B Prevalence of residual symptoms domains and pain, based on remission (HAMD-17 $\leq 7$ ) $N=412$, or non-remission (HAMD-17 $>7$ ) $N=212$.

After 3 months treatment, 66.0\% (412/624) of the patients were in remission (HAMD-17 $\leq 7$ ). Figure $1 \mathrm{~B}$ shows the prevalence of residual symptoms by remission status at 3 months. About 90\% of remitters (88.3\%; 95\% CI, 84.8-91.3) had residual symptoms from at least one of the domains studied.

Table 2 Residual symptoms, pain and HAMD-17 mean scores after 3 months of acute treatment, $N=624$

\begin{tabular}{ll}
\hline Residual symptom & Mean (SD) \\
\hline Core mood & $1.8(1.6)$ \\
\hline Anxiety & $1.8(1.4)$ \\
\hline Insomnia & $1.0(0.9)$ \\
\hline Somatic & $0.5(0.6)$ \\
\hline Pain & $16.0(18.4)$ \\
\hline HAMD-17 total score & $6.0(3.8)$ \\
\hline
\end{tabular}

$\mathrm{SD}=$ Standard deviation.

\section{Residual symptoms and patient functioning}

More than half of the patients $(59.4 \%, 371 / 624)$ had a normal level of functioning. Factors associated with normal functioning were absence of core mood symptoms (OR 8.7; 95\% CI, 4.6-16.7), absence of insomnia symptoms (OR 1.8; 95\% CI, 1.2-2.7), shorter episode length (4-24 weeks vs. $\geq 24$ weeks [OR 2.0; 95\% CI, 1.1-3.6]) and better baseline functioning (OR 1.0; 95\% CI, 1.0-1.1). A significant interaction was found between residual anxiety symptoms and pain $(\mathrm{p}=0.0080)$. The absence of pain increased the chance of normal functioning in either the absence (OR 21.7; 95\% CI, 3.5-132.5) or presence of residual anxiety (OR 1.7; 95\% CI, 1.0-2.8). However, the absence of residual anxiety was found to increase the chance of normal functioning only if pain was not present (OR 5.2; 95\% CI, 2.4.-11.3) (Table 3). Demographic variables, physical co-morbidities, baseline depression severity, previous depression episodes and residual somatic symptoms were not significantly related to functioning (Table 3). 
Table 3 Association between residual symptoms domains, pain and functioning

\begin{tabular}{|c|c|c|c|}
\hline \multirow[b]{2}{*}{ Age } & \multirow{2}{*}{$\begin{array}{c}\text { Odds Ratio } \\
0.990\end{array}$} & \multicolumn{2}{|c|}{ 95\% Wald Confidence Limits } \\
\hline & & 0.975 & 1.005 \\
\hline Gender (male vs. female) & 1.356 & 0.886 & 2.076 \\
\hline Academic degree (high vs. other) & 1.580 & 0.949 & 2.629 \\
\hline Baseline functioning level (SOFAS) & 1.049 & 1.031 & 1.067 \\
\hline Episode length (4-24 weeks vs. $\geq 24$ weeks) & 2.008 & 1.127 & 3.579 \\
\hline Episode lenght ( $\leq \mathbf{4}$ weeks vs. $\geq 24$ weeks) & 2.138 & 1.145 & 3.992 \\
\hline Absence of residual core mood symptoms & 8.728 & 4.553 & 16.730 \\
\hline Absence of residual insomnia symptoms & 1.796 & 1.175 & 2.744 \\
\hline Absence of residual anxiety symptoms and absence of pain & 5.257 & 2.445 & 11.300 \\
\hline Absence of residual anxiety symptoms and presence of pain & 0.412 & 0.073 & 2.341 \\
\hline Absence of pain and absence of residual anxiety symptoms & 21.669 & 3.544 & 132.498 \\
\hline Absence of pain and presence of residual anxiety symptoms & 1.700 & 1.025 & 2.819 \\
\hline
\end{tabular}

The AUC for the residual core mood symptoms was 0.84 (95\% CI, 0.80-0.87). Lower AUCs were found for the other residual symptom domains and pain: anxiety 0.75 (95\% CI, 0.71-0.78); pain 0.73 (95\% CI, 0.69-0.77); insomnia 0.65 (95\% CI, 0.60-0.69); and residual somatic symptoms 0.62 ( $95 \% \mathrm{CI}, 0.58-0.66)$.

\section{Discussion}

This study evaluated the relationship between patient functioning and specific residual symptom domains (core mood, insomnia, anxiety, somatic symptoms) and pain symptoms in a large group of patients with MDD who responded after receiving acute treatment. Anxiety was the most prevalent residual symptom, followed by core mood symptoms. The strength of the association between the residual symptom domains studied and patient functioning differed depending on the type of symptoms. A more marked association was found for residual core mood symptoms. Residual insomnia was less strongly related to patient functioning, and residual somatic symptoms were not associated.

To our knowledge, this is the first study to investigate the role of specific residual symptoms on patient functioning in MDD. Most publications about residual symptoms in MDD focus on their description and on their relationship to relapse and recurrence of depression [6,22-27]. More recent publications have evaluated their relationship to time to remission $[6,28]$. Few studies have specifically investigated the relationship between residual symptoms and functional impairment, but instead have focused on the overall impact of these symptoms on functioning without a separate analysis of the type of residual symptom $[1,8,29]$.

As reported previously, residual symptoms are very common after acute treatment, even in remitters
$[6,22,23]$. In the present investigation, we found that almost $90 \%$ of remitters had at least one residual symptom domain of mild intensity. This is similar to figures reported by Nierenberg et al. [6] and Ioveno et al. [22] Similar to other studies, the most common residual symptom domain in our patients was anxiety $[6,26]$. Other studies have reported residual insomnia [23] and sleep disturbances $[6,22]$ to be the most common residual symptoms domains. These differences may be due to the use of different scales and definitions. Development of a consensus on the definition and measurement of residual symptoms would be desirable to enable results between studies to be compared, thus improving understanding.

Interestingly, we found the strongest association between patient functioning and residual core mood symptoms, and we also found a significant interaction with pain and anxiety. The absence of pain increased the chances of normal functioning, regardless of the presence of residual anxiety. However, the absence of residual anxiety increased the chances of normal functioning only if pain was not present. Of note, we found residual insomnia significantly less strongly related to patient functioning than residual core mood symptoms. In addition, no association was found for residual somatic symptoms. It is remarkable that baseline depression severity and previous depression episodes were not significantly related to functional impairment. This further supports the previous finding that residual symptoms are more important than previous episodes of depression in the prognosis of the patient [5].

The different degree of association of each residual symptom with patient functioning might have prognostic implications and requires further investigation. In line with this, several recent studies tried to identify 
which specific residual symptoms are predictive of relapse or recurrence $[16,26,30,31]$. Residual anxiety symptoms were found to be predictive of relapse $[26,30,31]$. The picture for residual insomnia was less clear, with both positive $[16,30]$ and negative associations reported [6]. Although preliminary, these findings suggest that some residual symptoms present a greater risk for relapse than others.

This study has the following limitations: The primary study from which our data were drawn was not designed to assess residual symptoms, and our results are based on a post-hoc analysis. Our analysis has inherent limitations of post-hoc analysis; measures were those used in the source study. Antidepressant history, before baseline, was not collected, therefore percentage of naïve patients and already treated patients are unknown. This analysis has included a selected population of patients with MDD; patients who had a response to acute antidepressant treatment. This may limit the generalizability of the results to other types of patients not included in this analysis. Our research focused on selected residual symptoms domains and did not include domains such as fatigue or other symptoms not included in the HAMD-17. We also cannot rule out the possibility that a small proportion of the symptoms reported might have been treatment-emergent and not residual.

\section{Conclusions}

In summary, our results contribute to a better understanding of the role of specific residual symptoms domains on functional impairment in depression. We found that different residual symptoms have different degrees of association with patient functioning. This indicates that specific residual symptoms domains may be targets for intervention if normal functioning is the treatment objective.

\section{Competing interests}

Dr. Irene Romera, Dr. Antonio Ciudad, Pepa Polavieja and Dr. Inmaculada Gilaberte are employees of Eli Lilly. Dr. Irene Romera is also an affiliate with the Universidad Autónoma de Barcelona, Departamento de Psiquiatría. Dr. Victor Perez has received grant support from Eli Lilly, Lundbeck, Boehringer, Pfizer, Astra Zeneca, and GSK; has received honoraria from Servier, Eli Lilly, BMS-Otsuka, GSK, Astra Zeneca, and Boehringer; has served as a consultant for and/or on advisory boards for Eli Lilly, BMS, and AstraZeneca. Dr. Luis Caballero has served on advisory boards for Eli Lilly. Dr. Miguel Roca has received grant support from Almirall, Lundbeck and Janssen and served on advisory boards for Eli Lilly and Wyeth.

\section{Authors' contributions}

$I R$, PP and IG, have been involved in the analysis. All authors have been involved in the interpretation of the data, decision to submit the manuscript for publication and have read and approved the final manuscript. IR has been involved in writing the manuscript.

\section{Acknowledgements}

We thank Alistair Reeves for editing assistance, Ígor Martín from Chiltern International Inc. for his support with the statistical analysis, Irene Fregenal from Lilly Spain, Irene Fregenal from Lilly Spain for editing support, the principal investigators, and the patients for their voluntary participation. This study was funded by Eli Lilly and Company.

\section{Author details}

'Department of Clinical Research Lilly, S.A. Avenida de la Industria 30, 28108, Alcobendas, Spain. ${ }^{2}$ Autonomous University of Barcelona, Barcelona, Spain. ${ }^{3}$ Department of Psychiatry, Hospital Santa Creu i Sant Pau, Autonomous University of Barcelona / CIBERSAM, Barcelona, Spain. ${ }^{4}$ Department of Psychiatry, Hospital Puerta de Hierro, Madrid, Spain. ${ }^{5}$ Department of Psychiatry, Joan March Hospital, Rediapp, Palma de Mallorca, Spain.

Received: 23 January 2013 Accepted: 30 January 2013 Published: 11 February 2013

\section{References}

1. Romera I, Perez V, Menchón JM, Delgado-Cohen H, Polavieja P, Gilaberte I: Social and occupational functioning impairment in patients in partial versus complete remission of a major depressive disorder episode. A sixmonth prospective epidemiological study. Eur Psychiatry 2010, 25:58-65.

2. Zimmerman M, Posternak MA, Chelminski l: Heterogeneity among depressed outpatients considered to be in remission. Compr Psychiatry 2007, 48:113-117.

3. Paykel ES, Ramana R, Cooper Z, Hayhurst H, Kerr J, Barocka A: Residual symptoms after partial remission: an important outcome in depression. Psychol Med 1995, 25:1171-1180.

4. Pintor $L$, Torres $X$, Navarro $V$, Matrai $S$, Gastó $C$ : Is the type of remission after a major depressive episode an important risk factor to relapses in a 4-year follow up? J Affect Disord 2004, 82:291-296.

5. Judd LL, Akiskal HS, Maser JD, Zeller PJ, Endicott J, Coryell W, Paulus MP, Kunovac JL, Leon AC, Mueller TI, Rice JA, Keller MB: Major depressive disorder: a prospective study of residual subthreshold depressive symptoms as predictor of rapid relapse. J Affect Disord 1998, 50:97-108.

6. Nierenberg AA, Husain MM, Trivedi MH, Fava M, Warden D, Wisniewski SR, Miyahara S, Rush AJ: Residual symptoms after remission of major depressive disorder with citalopram and risk of relapse: a STAR*D report. Psychol Med 2010, 40:41-50.

7. Romera I, Pérez V, Menchón JM, Polavieja P, Gilaberte I: Optimal cutoff point of the Hamilton Rating Scale for Depression according to normal levels of social and occupational functioning. Psychiatry Res 2011, 30:133-137

8. Miller IW, Keitner GI, Schatzberg AF, Klein DN, Thase ME, Rush AJ, Markowitz JC, Schlager DS, Kornstein SG, Davis SM, Harrison WM, Keller MB: The treatment of chronic depression, part 3: psychosocial functioning before and after treatment with sertraline or imipramine. J Clin Psychiatry 1998, 59:608-619.

9. Keller MB: Past, present, and future directions for defining optimal treatment outcome in depression: remission and beyond. JAMA 2003, 289:3152-3160.

10. Ciudad A, Alvarez E, Roca M, Baca E, Caballero L, Garcia De Polavieja P, Casillas M, Valladares A, Gilaberte I: Early Response and Early Remission as Predictors of Good Outcome of a Depressive Episode. J Clin Psychiatry 2012, 73:185-191.

11. American Psychiatric Association: DSM-TR Diagnostic and Statistic Manual of Mental Health Disorders Text Revision, ed. 4. Washington: American Psychiatric Association; 2000.

12. Hamilton M: A rating scale for depression. J Neurol Neurosurg Psychiatry 1960, 23:56-62.

13. Guy W: 1976 ECDEU assessment manual for psychopharmacology. Rockville, Md. U. S: Dept. of Health, Education, and Welfare, Public Health Service, Alcohol, Drug Abuse, and Mental Health Administration, National Institute of Mental Health, Psychopharmacology Research Branch, Division of Extramural Research Programs; 1976:313-331.

14. Goldman HH, Skodol AE, Lave TR: Revising axis V for DSM-IV: a review of measures of social functioning. Am J Psychiatry 1992, 149:1148-1156.

15. Spitzer RL, Gibbon M, Endicott J, Mental Health Status, Functioning and Disability Measures. In Handbook of psychiatric measures: Global Assessment Scale (GAS), Global Assessment of Functioning (GAF) Scale, Social and Occupational Functioning Assessment Scale (SOFAS). Washington DC: American Psychiatric Association: 1st edition. Edited by First MB; 2000:96-100. 
16. Dombrovski AY, Cyranowski JM, Mulsant BH, Houck PR, Buysse DJ, Andreescu C, Thase ME, Mallinger AG, Frank E: Which symptoms predict recurrence of depression in women treated with maintenance interpersonal psychotherapy? Depress Anxiety 2008, 25:1060-1066.

17. DeLoach LJ, Higgins MS, Caplan AB, Stiff JL: The visual analog scale in the immediate postoperative period: intrasubject variability and correlation with a numeric scale. Anesth Analg 1998, 86:102-106.

18. Romera I, Fernández-Pérez S, Montejo AL, Caballero F, Caballero L, Arbesú $J A ́$, Delgado-Cohen H, Desaiah D, Polavieja P, Gilaberte I: Generalized anxiety disorder, with or without co-morbid major depressive disorder, in primary care: prevalence of painful somatic symptoms, functioning and health status. J Affect Disord 2010, 127:160-168.

19. Katz J, Melzack R: Measurement of pain. Surg Clin North Am 1999, 79:231-252

20. Bodian CA, Freedman G, Hossain S, Eisenkraft JB, Beilin Y: The visual analog scale for pain: clinical significance in postoperative patients. Anesthesiology 2001, 95:1356-1361.

21. Hosmer DW, Lemeshow S: Goodness-of-fit test for the multiple logistic regression model. Communication in Statistics - Theory and Methods 1980, 9:1043-1069.

22. Iovieno N, van Nieuwenhuizen A, Clain A, Baer L, Nierenberg AA: Residual symptoms after remission of major depressive disorder with fluoxetine and risk of relapse. Depress Anxiety 2011, 28:137-144.

23. McClintock SM, Husain MM, Wisniewski SR, Nierenberg AA, Stewart JW, Trivedi MH, Cook I, Morris D, Warden D, Rush AJ: Residual symptoms in depressed outpatients who respond by $50 \%$ but do not remit to antidepressant medication. J Clin Psychopharmacol 2011, 31:180-186.

24. Conradi HJ, Ormel J, de Jonge P: Presence of individual (residual) symptoms during depressive episodes and periods of remission: a 3-year prospective study. Psychol Med 2011, 8:1-10.

25. Benvenuti A, Rucci P, Calugi S, Cassano GB, Miniati M, Frank E: Relationship of residual mood and panic-agoraphobic spectrum phenomenology to quality of life and functional impairment in patients with major depression. Int Clin Psychopharmacol 2010, 25:68-74

26. Taylor DJ, Walters HM, Vittengl JR, Krebaum S, Jarrett RB: Which depressive symptoms remain after response to cognitive therapy of depression and predict relapse and recurrence? J Affect Disord 2010, 123:181-187.

27. Bertschy G, Haffen E, Gervasoni N, Gex-Fabry M, Osiek C, Marra D, Aubry JM, Bondolfi G: Self-rated residual symptoms do not predict 1-year recurrence of depression. Eur Psychiatry 2010, 25:52-57.

28. Roca M, García-Toro M, García-Campayo J, Vives M, Armengol S, García-García M, Asensio D, Gili M: Clinical differences between early and late remission in depressive patients. J Affect Disord 2011, 134:235-241. Epub 2011.

29. Ozyüksel B, Uluğ B: [The association between disability and residual symptoms in depressive patients: a 3-month follow-up.]. Turk Psikiyatri Derg 2007, 18:323-332.

30. Dombrovski AY, Mulsant BH, Houck PR, Mazumdar S, Lenze EJ, Andreescu C, Cyranowski JM, Reynolds CF: Residual symptoms and recurrence during maintenance treatment of late-life depression. J Affect Disord 2007. 103:77-82.

31. Yang H, Chuzi S, Sinicropi-Yao L, Johnson D, Chen Y, Clain A, Baer L, McGrath PJ, Stewart JW, Fava M, Papakostas GI: Type of residual symptom and risk of relapse during the continuation/maintenance phase treatment of major depressive disorder with the selective serotonin reuptake inhibitor fluoxetine. Eur Arch Psychiatry Clin Neurosci 2010, 260:145-150.

doi:10.1186/1471-244X-13-51

Cite this article as: Romera et al:: Residual symptoms and functioning in depression, does the type of residual symptom matter? A post-hoc analysis. BMC Psychiatry 2013 13:51.

\section{Submit your next manuscript to BioMed Central and take full advantage of:}

- Convenient online submission

- Thorough peer review

- No space constraints or color figure charges

- Immediate publication on acceptance

- Inclusion in PubMed, CAS, Scopus and Google Scholar

- Research which is freely available for redistribution

Submit your manuscript at www.biomedcentral.com/submit 